\title{
Assessment of Testosterone Hormone Level in Patients with Toxoplasmosis Attending Omdurman Military Hospital
}

\author{
${ }^{1}$ Ibrahim Altigany ${ }^{1}$, Suhair. A. Ahmed ${ }^{2}$, Abd Elkarim A. Abdrabo ${ }^{3}$ \\ ${ }^{1}$ Department of Laboratory, Military Hospital \\ ${ }^{2,3}$ Department of Clinical Chemistry, Faculty of Medical Laboratory Sciences, Al-neelain University- Sudan
}

\begin{abstract}
Objective: to evaluate and compare serum testosterone in patients with toxoplasmosis and normal healthy individuals. Materials and Methods: A case control study was conducted in 150 subjects in military hospital, during the period from February to June 2015. The studied population consisted: 100 patients already diagnosed as toxoplasmosis patients (58 male and 42 female) as cases and 50 apparently healthy individuals (32 male and 18 female) as controls. Five $\mathrm{ml}$ of The blood samples were collected and sera separated by centrifugation at $4000 \mathrm{rpm}$. the serum testosterone levels were accurately measured and compared. Results: We found significantly increasing in serum testosterone levels in toxoplasmosis patients as compared to control (p=0.000). also we found significantly increasing in serum testosterone levels inmale patients as compared to control male(p=0.000), also a significantly increasing in serum testosterone levels in female as compared to control female $(p=0.000)$. also we found significantly increasing in serum testosterone levels in patient male as compared to patient female( $p=0.001)$. Conclusion: These findings concluded that toxoplasmosis is associated with higher serum testosterone levels.
\end{abstract}

Keywords: Toxoplasma infection, testosterone

\section{Introduction}

Toxoplasma gondii is an intracellular protozoan parasite that infects human and animals. Infection by toxoplasma gondii is widely prevalent in human and animals throughout the world, and of both veterinary and medical importance, because it may cause abortion, fetal death, and stillbirths in its intermediate hosts. Although toxoplasmosis is a cosmopolitan infection, the disease appears to be overshadowed in the tropics by other endemic diseases like malaria and enteric fever. With the realization of toxoplasmosis as an opportunistic infection in AIDS, renewed interest has emerged in the epidemiology of toxoplasmosis in Africa. Recent surveys have shown wide variations in the prevalence and epidemiologic pattern of toxoplasmosis in different African countries Somalia 43.6[1] Mauritania $14.5 \%[2]$, Kenya 54\%[3],Nigeria 58.9\%[4] ,Libya 52\%[5],Burundi 41.1\%[6] ,Niger 18.2\%)[7], in Sudan the only information available on the prevalence of toxoplasmosis dates back to 1966 (Carter \&Fleck 1966).

This parasite has been reported to cause four types of disease. The most dangerous is congenital toxoplasmosis, which often results in serious damages to fetus and development of various symptoms like micro-cephalic, hydro-cephalic and mental problems in infants [8]. The Second form is acute postnatal acquired toxoplasmosis. This form recognized by the presence of tachyzoite in blood and other tissues. A wide range of clinical symptoms like cervical lymphadenopathy, fever, headache, psychiatric and neurological complications can be found in immunocompetent patients. But symptoms of acute toxoplasmosis are usually mild and harmless. Accordingly, toxoplasmosis is usually misdiagnosed with bacterial or viral diseases[8].
Lower cellular immunity which is associated with high levels of steroid hormones contributes to the survival of the parasite in the body. Such these people, cause of steroid hormones increase with weak immune system, contribute to this parasite survive in body[9]. Other reports indicate that Toxoplasma can increase the number of son and reproductivity[10].It is likely that sexual hormones changes can play an important certain role in relation with Toxoplasma and aforementioned phenomena. Patients suffer from chronic toxoplasmosis are taller than uninfected ones, and sexual hormones concentration, testosterone, is higher than uninfected people, and also sexual maturity age of infected men is lower that uninfected men[11]. Increased dopamine and testosterone levels are suspected to play an important role in theobserved changes[12]. However, the association between toxoplasmosis and increased testosterone concentration was only postulated on the basis of indirect evidence. Infected men are taller, have a lower left hand 2D:4D ratio[13]. Infected women have a(nonsignificantly) lower left hand 2D: 4D ratio and are more likely to give birth to a boy than a girl[14]. All these traits are known to be positively associated with testosterone concentration in human [15].

\section{Materials and Methods}

This was a prospective case control study conducted in military hospital in Khartoum, Sudan during the period from February 2015- June 2015. The case group was composed of 100 patients with toxoplasmosis while the control group was composed of 50 apparently healthy individuals.

A coded enrollment number was given for each enrolled subject. The data were collected by using a direct interviewing questionnaire. Medical information was collected from the patients. The questionnaire was used to 


\section{International Journal of Science and Research (IJSR) \\ ISSN (Online): 2319-7064}

Index Copernicus Value (2013): 6.14 | Impact Factor (2014): 5.611

collect data regarding name, age, gender. Five ml venous blood were collected from each enrolled subject and poured into plain containers, left at R.T for one hour and centrifuged at $4000 \mathrm{rpm}$ for three minutes to obtain sera. Sera obtained were analyzed for testosteroneusing Roche and Hitachi E411analyzer,which is fully automated micro plate system Elecrtochemiluminescenselmagnetic particle. The data were analyzed using the statistical software package SPSS, version 20.0

\section{Results}

A total of 150 subjects were enrolled in the study. 100 of them were toxoplasmosis patients (58 male and 42 female) as cases and 50 apparently healthy individuals ( 32 male and 18 female) as controls. The statistical findings were illustrated as follows : showed that serum levels of testosterone in toxoplasmosis patients( $7.62 \pm 2.64 \mathrm{nmol} / \mathrm{l}$ )were significantly higher than those of control $(3.42 \pm 3.01 \mathrm{nmol} / \mathrm{l})$ with $\mathrm{p}$ value $(0.000)$ as shown in table (1) and fig (1), also fig(1) showed comparison between mean level of testosterone in male and female subjects control and patients

There is statistical significant difference in the serum levels of testosterone, between toxoplasmosis females $(6.57 \pm 2.46$ $\mathrm{nmol} / \mathrm{l})$ and males, $(8.34 \pm 2.52 \mathrm{nmol} / \mathrm{l}](\mathrm{p}=0.001)$ as shown in table (2).

Table 1: showed the mean level of testosterone between toxoplasmosis patients and control

\begin{tabular}{|c|c|c|c|}
\hline & $\mathrm{N}$ & Mean \pm Std. Deviation & $* \mathrm{p}$ value \\
\hline Patient & 100 & $7.622 .6 \pm 4 \mathrm{nmol} / 1$ & 0.000 \\
\cline { 1 - 3 } Control & 50 & $3.42 \pm 3.01 \mathrm{nmol} / 1$ & \\
\hline
\end{tabular}

level of $<(0.05)$

Table 2: showed the comparison of test osteronemean level between toxoplasmosis Malepatients and Female patients

\begin{tabular}{|c|c|c|c|}
\hline & $\mathrm{N}$ & Mean \pm Std. Deviation & $* \mathrm{p}$ - value \\
\hline Male & 58 & $8.39 \pm 2.52 \mathrm{nmol} / 1$ & \multirow{2}{*}{0.001} \\
\cline { 1 - 3 } Female & 42 & $6.57 \pm 2.46 \mathrm{nmol} / 1$ & \\
\hline
\end{tabular}

$* p$ value showed a statistical significance difference at level of $<(0.05)$

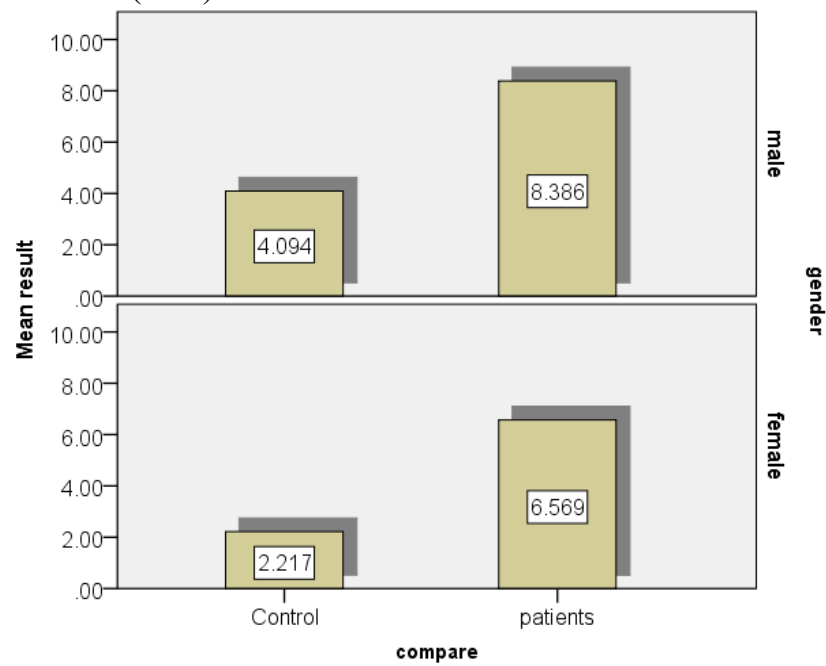

Figure 1: Showed the comparison of Testosterone mean level between patients and control (Males and Females).

\section{Discussion}

The present study is conducted for exploring the relation between Toxoplasma infection and level of testosteronehormone. Our study demonstrated that there is a significant correlation between testosteronehormones levels and toxoplasma infection. But it should be noted that serum testosterone concentrations in cases and controls were within the normal range.

Toxoplasma is one of the almost widespread parasite diseases common between human and warm-blood animals, which is widely distributed around the world. In Africa, its prevalence is different in various countries; Somalia $43.6 \%$,Mauritania $14.5 \%$, Kenya $54 \%$,Negeria $58.9 \%$,Libya $52 \%$,Burundi $41.1 \%$,Niger $18.2 \%$, in warm weather and lowlands is more widespread than mountains.

The main ways of parasite and Toxoplasma infection transmission is consuming raw or semi cooked meat infected with $T$. gondii or infected cat feces, and also congenital through placenta to fetus, drinking unpasteurized milk and even blood transfusion, transplantation and semen reception [16].

Our research results indicated that there is a direct relation between Toxoplasma infection and testosterone increase in serum

Results indicated that testosterone levels in the infected individuals is higher in both infected men and women than uninfected ones. Testosterone increase significantly in patient male as compared to patient female. The studies that have been conducted by some researchers indicate that there is a relation between chronic toxoplasmosis and disturbance of the reproductive parameters in male animals [17].Terpsidis et al. studied the influence of toxoplasmosis on male reproductive parameters. Their results showed marked increasing of sperm abnormalities in infected mice. In this study, toxoplasmosis could affect main reproductive parameters in male rats, which are the most predictive of their fertilizing capacity[17]. Arantes et al. studied the presence of $\mathrm{T}$. gondii in semen, testicle and epididymis of dogs experimentally infected. The parasite was present in these tissues. Artificial insemination of female dogs with $\mathrm{T}$. gondii positive seminal samples induced the serologic conversion. These results suggest that $\mathrm{T}$. gondii can be sexually transmitted in domestic dogs[18].

Kankova et al. studied changes in the testosterone levels in the latent phase of toxoplasmosis in laboratory mice artificially infected with cystogenic but relatively virulent strain T38 of T. gondii. Testosterone levels in both female and male mice with latent toxoplasmosis were decreased in comparison to uninfected controls [19]. Whereas previous studies (17-19) could not determine whether Toxoplasma infection induces changes in testosterone concentration or whether low and high testosterone subjects differ in the probability of acquiring Toxoplasma infection. The former hypothesis is correct and toxoplasmosis influences the level of testosterone. 


\section{International Journal of Science and Research (IJSR) \\ ISSN (Online): 2319-7064 \\ Index Copernicus Value (2013): 6.14 | Impact Factor (2014): 5.611}

Increased concentrations of testosterone to have immunosuppressive effects, according to this the decrease of testosterone concentration could be an adaptive response of infected mice to Toxoplasma-induced immunosuppression [19].

The opposite direction of the testosterone shift in men compared to women can explain the observed gender specificity of behavioral shifts in Toxoplasma-infected subjects [20].

Oktenli and colleagues announced the transient hypogonadotrophic hypogonadism in men is not rare in toxoplasmosis [21]. His results were consistent with the results of experimental studies in animals (22-24).

\section{Conclusion}

It is concluded that Toxoplasma infection increase Testosteronelevel. Besides, since it is probable that parasite presence in the body leads to blood testosterone increase, it is suggested that its accuracy be explored in the next researches.

\section{References}

[1] Zardi O., Adorisio 8., Flarare O. \& Nuti M. (1980) Serological survey of toxoplasmosis in Somalia. Transactions of the Royal Society of Tropical Medicine and Hygiene74,577-581.

[2] Monjour L., Niel G., Palminteri M., Sidatt C., Ribeiro C., Alfred C. \& Gentilini M. (1983) An epidemiological survey of toxoplasmosis in Mauritania. Tropicaland Geographical Medicine 35, 21-25.

[3] Griffin L. \& Williams K. A. B. (1983) Serological and parasitological survey of blood donors in Kenya for toxoplasmosis. Transactions of the Royal Society of Tropical Medicine and Hygiene 77,763-766.

[4] Arene F. O. I. (1986) The prevalence of toxoplasmosis among inhabitants of the Niger delta. Folia Parasitologica 33, 31 1-314.

[5] Khadre M. A. \& El Nageh M. M. (1987) Serological survey for toxoplasmosis in Tripoly S.P.L.A.J. (Libya). Transactions of the Royal Society of Tropical Medicine and Hygiene 81, 761-763.

[6] Excler j. L., Pretat E., Pozzetto O. B., Charpin B. \& Garin J.P.(1988) Sero-epidemiological survey of toxoplasmosis in Burundi. Tropenmedizin und Parasitologie 39, r39-t41 .

[7] Develoux M., Candolfi E., Hanga-Doumbo S. \& Kien T. (1988) Latoxopiasmose auNiger. Bulletin de la Societe de Pathologie Exotique 81, 253-259.

[8] Flegr J, Hrdá S, Kodym P. Influence of latent 'asymptomatic' toxoplasmosis on body weight of pregnant women. Folia Parasitol. 2005; 52: 199-204.

[9] Raquel Coelho AL, Kobayashi M, Carvalho LB Jr. Prevalence of IgG antibodies specific to Toxoplasma gondii among blood donors in Recife. Northeast Brazil. Revista do Instituto de Medicina Tropical de Sao Paulo. 2003: 45: 229-34

[10] Saebi E. Parasite diseases in Iran. 6th ed, Tehran, Cultural Institute. 1998: 251-41.

[11] Jones JL, Ogunmodede F, Schftel J, Kirkland E. Toxoplasmosis-related knowledge and practices among pregnant women in the United States. Infect Dis Obstet Gynecol. 2003: 11: 139-45.

[12] J. flegr, J. lindova and P. kodym . sex-dependent toxoplasmosis-associated differences in testosterone concentration in humans . 2007: 1 .

[13]Flegr, J., Hruskova, M., Hodny, Z., Novotna, M. and Hanusova, J. (2005). Body height, body mass index, waist-hip ratio, fluctuating asymmetry and second to fourth digit ratio in subjects with latent toxoplasmosis. Parasitology 130, 621-628 .

[14] Kan`kova', S` ., S` ulc, J., Nouzova' , K., Fajfrlı'k, K., Frynta, D. and Flegr, J. (2007). Women infected with parasite Toxoplasma have more sons.

[15] James, 1986, 1996; Drop et al. 1998; Brown et al. 2002; Okten et al. 2002; Neave et al. 2003; Lutchmaya et al. 2004.

[16] O'Keane V, Marsh MS. Depression during pregnancy. BMJ. 2007; 334: 1003-5.

[17] Terpsidis KI, Papazahariadou MG, Taitzoglou IA etl.. Toxoplasma gondii: Reproductive parameters in experimentally infected male rats. Exp Parasitol. 2009; 121(3):238-41.

[18] Arantes TP, Lopes WDZ, Ferreira RM, et al. Toxoplasma gondii Evidence for the transmission by semen in dogs. Exp Parasitol. 2009;123(2):190-4.

[19] Kaňková Š, Kodym P, Flegr J. Direct evidence of Toxoplasma-induced changes in serum testosterone in mice. Exp Parasitol. 2011;128(3):181-3.

[20]Flegr J, Lindová J, Pivoñková V, Havlíček J. Brief Communication: Latent toxoplasmosis and sali-vary testosterone concentration-Important con-founding factors in second to fourth digit ratio studies. Am J Phys Anthropol. 2008;137(4):479-84.

[21] Oktenli C, Doganci L, Ozgurtas et al. Transient hypogonadotrophic hypogonadism in males with acute toxoplasmosis: suppressive effect of inter-leukin $1 \beta$ on the secretion of GnRH. Hum Reprod. 2004; 19(4):85966.

[22] Stahl W, Dias JA, Turek G. Hypothalamicadenohypophyseal origin of reproductive failure in mice following chronic infection with Toxoplasma gondii. Exp Biol Med. 1985;(178):246-9.

[23] Stahl W, Kaneda Y, Noguchi T. Reproductive failure in mice chronically infected with Toxoplasma gondii. Parasitol Res. 1994;80(1):22-8

[24] Antonios S, Ismail H, Essa T. Hypothalamic origin of reproductive failure in chronic experimental toxoplasmosis. J Egypt Soc Parasitol. 2000; 30 (2):5939. 